\title{
Gender Biases against Women in the Workplace
}

\author{
James, C. Klutsey \\ A second year Doctoral Candidate \\ Department of Educational Leadership \& Counseling \\ Florida Agricultural \& Mechanical University \\ Email:jamesghana2011@yahoo.com OR \\ James1.klutsey@famu.edu
}

Tel: 850-567-3028

\begin{abstract}
Throughout the years, many organizations have experienced a plethora of issues regarding gender bias. In this study, my literature review has revealed that a significant proportion of gender bias emanates from upper management in almost every organization. This research paper examines and discusses gender discriminations (isms) explored as biases against women and men in the workplace. The study has revealed that a plethora of leaders are products of their upbringings, and stereotypes can influence the number of promotions and backlash effects that they can receive in their careers. In this write-up, socialization relating to male and female, stereotyping in terms of male vs. female, job promotion in male vs. female, backlash effects relating to male and female employed as (isms)in this study. Lastly, I provided several strategies that organizations could implement to eliminate gender bias in the workplace.
\end{abstract}

Keywords: backlash, promotion, socialization(isms) genderism, self-identity, intersectionality, oppression, biases, discrimination, leadership, gender

Genderism is the discrimination caused due to the belief that one gender is superior to another. The notion that men are superior to women is problematic andneeds critical examination because gender issues create critical matters in the workplace. For it may create workplace conflict that has severe repercussions for the organizations as well as individuals working in those organizations. This belief was the reason why the word genderism came into existence, making people feel different. All the ism words are related to biases or discrimination against one person or another. This paper discusses ism as a form of discrimination concerning socialization in male vs. female, stereotypes relating to male vs. male, job promotion relating to male vs. female, and backlash effects of stereotyping female and male leaders.

\section{Socialization: Childhood Factors that Shape Leadership Styles}

Gender socialization is described as the process of males and females becoming aware of the norms and behaviors associated with their sexes. Gender socialization, concerning the workplace and leadership, is a cultural process that starts at birth. This process introduces girls and boys to the various cultural and societal behaviors and gives them the task of adhering to their physical characteristics, more specifically, gender. For example, in Africa, specifically the Volta Region of Ghana, the male child is associated with fatherhood and the work that his father does while the girlchild is taught to work with her mother, especially in cooking at home. Even though I see this cultural practice as something excellent and commendable, with time this practice has begun to fade out since many girls feel oppressed. The girl-child believes that she can also do the work of the male-child by helping her father on the farm and vice versa on the part of the boys. The gender socialization encourages and makes the individual child understand who he/she is, and this is what we callself-identity. This self-identify helps the boy or girl to appreciate his or herstrengths and weaknesses, beliefs, culture and values, among others, to make informed decision.

Previous gender socialization studies, often classified as role socialization, attempted to make a connection between childhood gender role differentiation, leadership qualities, and style characteristics (Smith \& Rogers, 2000) as cited in Johnson \& Johnson, Joseph, \& Klutsey (2015).In a review of male and female differences, concerning occupation, Smith, and Rogers attempted to show that a dimension of ethical decision making is linked to male and female early childhood socialization. The researcher pointed out that feminine norms and behaviors, such as agreeableness placed on interpersonal relationships and having a holistic view. However, a different outlook contrasted with the male individualistic competitiveness, disjointed (separate) perspective, and risk-taking characteristics (Smith \& Rogers, 2000) as cited in Johnson \& Johnson, Joseph \& Klutsey (2015). 
Besides, for example, fathers who teach their sons how to fish, hunt, and play sports exhibited how male early childhood socialization helps to shape a young boy's future roles in leadership. It develops in the child characteristics, which are desirable traits for top management positions. While young females spend most of their free time socializing with their friends and reading, young males tend to focus on sports and acquiring specialized skills and knowledge, which according to researchers, Nickel and Vale (1988), are behaviors reinforced from early childhood socialization. Many of the qualities and characteristics displayed as leadership traits are primarily linked to the male because of the overwhelmingly patriarchal business environment and viewpoint. Looking at most business models and leadership styles, it is apparent that $85 \%$ of current Fortune 500 companies have male CEOs and are driven by overtly masculine traits, such as individualism (Soares, 2012). In these companies, managers place less importance on developing interpersonal relationships, while more attention is placed on what the employees have accomplished or what they can do for the business to improve performance and profits (Warner, 2014).

As previously mentioned, there is a shift in women becoming more driven to achieve goals that were once viewed as male oriented. Women are now emerging in leadership roles and vying for spots, which were once reserved for men. Previous views on male and female social functions are now beginning to expand to include overlapping of the last gender defined roles, which were not so prevalent in the past. Current research on male and female gender socialization focuses on how people can help equalize these cultural gender identification patterns to enhance the acceptance of a "grey area" of roles and characteristics. As a result, both females and males will be able to cultivate and benefit from these characteristics. According to Ulkuer (2006), the global community that advances the efforts of equalizing the gender roles by taking a hard look at the perpetuated masculine and feminine dichotomy; the city should also focus on minimizing the notion of gender-exclusive traits and being open to the possibility of combining some of the characteristics of these defined roles. Ulkuer (2006) compiled the following list of possible solutions to help bridge the gap between gender socialization inequalities:

- we can start with what parents, children, and local leaders do and say about gender expectations, and identify the point of entry and opportunity for promoting change, map gender roles in specific settings and understand places were change already exists, and how to change tapped or accelerated,

- assess the environment for young children at home and examine how a small environment may influence a boy's learning in school and what deprivation may hinder it,

- foster greater engagement of men in the care of children,

- focus on parenting and child-rearing patterns in the family (including the extended family) and community,

- focus on group learning opportunities (including daycare centers, pre-schools, and the early years of primary school), and

- We must focus on parents of both sexes, as well as on community religious leaders, by encouraging parental involvement in adult education classes. There should be integration of religion and a formal western curriculum so that they can see the need for and the benefits of literacy for their daughters and wives.

\section{Stereotypes Surrounding Male and Female Leaders (genderism)}

Even though the world is not entirely free of gender biases, many people are starting to break down the barriers. It takes more than a century for women to be equal in men's eyes. Stereotyping is a phenomenon that happens every day to men and especially to women in the upper level of the workforce. The abundance of women is still not receiving as much compensation for their work as men, even though they are in the same positions. One of the most common stereotypes in the workplace involves women being too sensitive; on the other hand, a male leader can be viewed as emotionless, and he would still receive praise from his peers for achieving a goal. Another stereotype involves women and men only being fit for certain types of jobs. For example, a lot of organizations do not want women to lead the finance or accounting departments. Also, some organizations will not promote a man as a head nurse because they believe that he will not be sensitive enough to communicate with patients and their families. These isms in the workplace have existed for far too long. It has affected women most in every organization as well as in every society. Though some men also suffer similar biases in some workplaces, this stereotyping effect leads to intersectionality, which creates room of oppression for men and women in the workplace.

In Heilman's research (2012), many stereotypes that women and men experience in the workplace are identified. These stereotypes are classified into two different categories: descriptive stereotypes and prescriptive stereotypes. Descriptive stereotypes involve designating what women and men are like, while rigid stereotypes affect identifying what women and men should be like in their careers (Heilman, 2012, p. 113), as cited in Johnson \& Johnson, Joseph, \& Klutsey (2015). Moreover, women have received more backlash effects when they have low levels of organizational-fit. According to Heilman (2012), "research has provided evidence that there is a perceived lack of fit between the demands of high-level organizational positions and characterizations of women. Often, the main reason why men are 
more likely to be in high situations is that a male is generally the CEO of the company; as a result, the CEO will prefer having male leaders around him. Also, women will tend to receive more negative feedback when the organization perceives a specific job as being fit for a male. Negative evaluations in selection decisions have repeatedly been found to occur more for male gender type jobs than other types of jobs, and there are similar findings concerning competency assessments and performance evaluation (Heilman, 2012).

Furthermore, prescriptive stereotypes cover how a woman and a man should act in the workplace. This stereotype can be more intense than descriptive stereotypes because there are penalties that are given out to employees if they do not follow the set norms. For women, the commonality prescribed is that not only is it thought that women are communal, but it is also believed that they should be cooperative and be demonstrating socially sensitive and nurturing attributes reflecting their concern for others (Heilman, 2012). Prescriptive stereotypes are generally described as the attributes that men and women should possess. Some of the characteristics that should not be displayed by women concern the different behaviors that are associated with men. These attributes include self-assertion, dominance, and achievement orientation (Heilman, 2012, p. 123). Additionally, some of the penalties for violating the norms in the workplace include receiving inadequate evaluations by coworkers. Also, "a breach of gender-related prescriptions has additionally been shown to result in more tangible penalties, including lower pay, less intention to hire and promote, and fewer recommendations for organizational rewards" (Heilman, 2012, p. 123). For women to migrate to the corporate ladder, they must break the values and norms. A female leader must be aggressive and willing to suffer the consequences of her actions.

Moreover, leadership styles differ for men and women; female leaders are stereotyped as being more non-aggressive when taking actions. For example, many female leaders discipline their employees in a private room, rather than in front of their coworkers. However, male leaders have more of a democratic style of leading in the workplace.During the evaluation process, they tend to give lesser feedback to employees than female leaders do.Also, negotiating salaries when climbing the corporate ladder should be acceptable for both male and female employees, but it is the opposite. Women tend to be more hesitant and critical to negotiate this aspect of their careers. According to Heilman (2012), "salary is so central to the work experience, and in many cases is considered a measure of one's worth, both to self and to others. This failure to advocate for oneself has captured the attention of many researchers" (p.124). Women who are more vocal about negotiating their salaries, generally get punishments than men; women who voice their opinions are often not hired, or they are viewed negatively by their organizations.Men can also receive penalties for acting out in specific ways. "When men failed to help with a physically demanding male-typed citizenship behavior, they were regarded more negatively and rewarded less generously than women who did the same. Men, too, are held to gender stereotypes and are penalized when they do not conform to them" (Heliman, 2012, p. 128). Men who are successful in women-dominated jobs are often criticized because their coworkers see them as being passive and soft. The results appear to be at odds with research indicating that men ride the glass elevator in female occupations, receiving greater organizational rewards and making quicker career progress than similarly qualified women (Heilman, 2012, p. 129). It is concluded that men who work in women-dominated organizations (as well as male-dominated organizations) will always become successful and move up in their careers. On the other hand, women do not receive the same treatment unless they follow the rules of their organizations.

\section{Job Promotions: Male vs. Female Leaders}

Stereotypes regarding gender cause many supervisors to engage in the illegal practice of overlooking a person for promotion. While I see that in both genders, supervisors often overlook women for promotions because of preconceived notions about their roles and abilities. For example, fire chiefs may repeatedly ignore a female firefighter for development because they may believe that a man will perform better; this stereotype generally based on the job being physically demanding. However, some supervisors may overlook qualified males for promotions in certain industries that employ a high percentage of women compared to men, such as teaching and child-care positions.

Furthermore, a promotion can be influenced heavily by the policies and practices that are utilized in an organization. Shackelford (2011) noted that current policies and practices are useful tools for managing the subtle forms of biases. The author argued that society had conditioned us to equate certain professions (or positions) with a gender, and this conditioning is where the unintentional and subconscious biases reside (para. 9), as cited in Johnson \& Johnson, Joseph, \& Klutsey (2015). In general, society has viewed gender stereotyping as a driving force for gender biases, which can influence a supervisor's decision to hire or promote an individual. For instance, when selecting between two equally qualified candidates, raters often will choose a candidate who matches his /her stereotypical picture of the right fit for the position to arrive at a decisive decision accentuating the positive attributes of the traditional candidate and, likewise, focusing on the negative characteristics of the other candidate" (Shackelford, 2011, para. 10)as cited in Johnson \& Johnson, Joseph, \& Klutsey (2015). 
According to Powell and Butterfield (1994), "women have made considerable progress in entering the managerial ranks of U.S. enterprises in recent years, but not at the highest levels. The proportion of women managers increased from sixteen percent in 1970 to a 1992 level of forty-two percent; however, the proportion of women who hold top management positions increased only slightly" (p. 68). In return, this slight increase has created a glass ceiling to prevent women from excelling in their careers. "Although the glass ceiling could exist at different levels in different organizations or industries, the term is typically used to suggest a barrier to entry into top-level management positions" (Powell \& Butterfield, 1994, p. 69). This barrier is unfair because a plethora of organizations have decided to promote males in top-level positions, regardless of the fact female candidates were more qualified.

Moreover, the proportion of women receiving advanced degrees varies enormously from time to time, especially in psychology, one of the sciences, which elevates the highest performance of women. For example, fifty-eight percent of PhDs awarded in psychology go to women; unfortunately, academia in psychology is disproportionately a male endeavor" (Steinpreis, Anders, \& Ritzke, 1999, p. 510). Even though there are gender biases in this specific field, many female professors are not aware that they exist, dough if they experience barriers. These barriers include but are not limited to isolation, lack of peer and administrative support, increased likelihood of having to balance child-care responsibilities, lower income than their male counterparts and lower statuses in their institutions (Steinpreis, Anders, \& Ritzke, 1999, p. 510). One of the reasons why a female professor may overlook the barriers as a form of gender discrimination is that she might be solely focusing on her student successes. According to Esteze-Abe (2005), even when women are determined to put their careers first, they still face problems because of the employer's fear that women are more likely than men to quit (p. 190). Many organizations believe that women cost significantly more than men to employ. They further insist that women are different from men because they are more likely to interrupt their work-life to attend to their family needs (Esteze-Abe, 2005, p. 190). Therefore, the costs associated with employing women are usually linked to the number of days that they take off their work. As organizations analyze these expenses, they generally compare them to the amount spent on recruiting and training initiatives annually. If the costs are unbalanced, then they may become more sensitive during the hiring process to keep their employee turnover ratio low. This stereotyping means that many organizations will have a higher chance of discriminating against female candidates than male candidates.

\section{The Backlash Effects of Stereotyping Female and Male Leaders}

Stereotypes dictate what men and women ought (and ought not) to do as a set of gender rules which powerfully shape expectations for human behavior (Moss-Racusin, Phelan, \& Rudman, 2010, p. 140) as cited in Johnson \& Johnson, Joseph, Klutsey (2015). Often, female leaders experience backlash if other people in the organization believe that they are not meeting their expectations. According to Rudman and Phelan (2008), the backlash on the job from coworkers can negatively impact the women's work experiences; female coworkers and subordinates will often react negatively to other women's successes (p. 67). Many of them will respond negatively to female leaders because they believe males should generally hold those leadership positions. As a result, female coworkers may undermine their authority and even start false rumors about female leaders. The coworkers may also respond in negative terms when they are jealous of another female promoted in an organization. The jealousy will frequently occur if a female coworker believes that she should have received the promotion. Once this has happened, the female coworker may become reluctant to follow commands by the new female leader.

Moreover, many female leaders will begin to implement the impression management strategy, self-promotion, to convince their female coworkers that they have the abilities and skills to perform successfully. However, this specific strategy can cause female leaders to experience a form of backlash. Many people in the workplace will generally perceive female leaders who self-promote their abilities as being arrogant. According to O'Neill and O'Reilly (2011), when they conducted the masculine experiment on female managers, they found traits of confidence, toughmindedness, self-assurance, and aggressiveness expected in the male stereotype. They violate the female gender role but negatively evaluated. Although masculine women are seen it as more competent than feminine women, they are also seen as less socially skilled and, consequently, less likable and less likely to be promoted (p. 826). Research suggests that male managers tend to give promotions to female leaders who accept their initial offer, rather than those who try to negotiate their salaries (Moss-Racusin \& Rudman, 2010).

Female leaders can also notice signs of backlash after receiving the results of their performance evaluations. According to Rudman and Phelan (2008), a woman who navigates the double standard of the agency to obtain a high-powered position the job continues to pay the price for stereotype disconfirmation. Even though it may be required for career success; women are expected to be kind, but if leadership behaviors deviate from this expectation, their evaluations suffer. In a male-driven organization, employees tend to evaluate a female leader negatively because they are comparing her to the stereotypes that surround men. For example, some female leaders tend to score poorly on their 
performance evaluations when the employer uses intimidation or punishment strategies as a method of accomplishing goals or when they deliver discipline to employees" (Rudman \& Phelan, 2008, p. 67). As a result, scoring poorly on a performance evaluation can cause a female leader to be penalized or even sacked from the organization. Even though male leaders tend to experience fewer negative stereotypes than female leaders in the workplace, they can still face a form of backlash. Often, their backlash is overlooked because a plethora of people will commend them for being able to climb the corporate ladder faster than females.

Historically and cross-culturally, men are stereotyped as more agentic (i.e., independent and self-focused) than women, and women as more communal (i.e., other-oriented and modest) than men (Moss-Racusin, Phelan, \& Rudman, 2010, p. 140). Research emphasizes that male leaders will continuously be viewed on a larger scale than female leaders for approximately fifty more years (Moss-Racusin, Phelan, \& Rudman, 2010). Eventually, this type of viewpoint can cause the male leaders to experience more backlash as they violate and adhere to the unwritten gender rules in an organization.

Many people believe that male leaders should maintain high levels of strength, aggression, and masculinity if they want to manage an organization correctly. According to Moss-Racusin, Phelan, \& Rudman (2010), "walk tall" " be a man" and "do not be a sissy" are familiar phrases that underscore the extent to which gender stereotypes generally call for men to be strong and proud. This expression means that male leaders should never let other people observe their weaknesses. However, once a male leader has broadcast his flaws, he can experience a backlash. By showing flaws, the male leader is viewed as having a feminine personality, which is far from the ideal characteristics (i.e., dominant and successful) placed in many employees' minds. Violating the gender rule can also cause social and economic penalties. "For example, men who self-disclose their problems are perceived less favorably than women who do it (Moss-Racusin, Phelan, \& Rudman, 2010, p. 140). After this has occurred, it can cause a top manager to demote the male leaders because theyare perceived as being unable to fulfill their duties.

Moreover, some people may think that male leaders cannot experience backlash if they do not adhere to the unwritten gender rules in an organization. However, non-adherence to masculine norms and stereotypes has been linked to negative consequences for men, suggesting that liberating men from the bonds of traditional masculinity would be beneficial (Moss-Racusin, Phelan, \& Rudman, 2010, p. 140). By adhering to the rules, male leaders can harm their relationships in the organization. This relationship tends to happen once the men have increased their level of aggression to overestimate their abilities. Often, the enhanced attack will cause some of the female employees to become fearful and will minimize their social relationships. Also, male leaders can cause harm to themselves as they display more aggression. "For example, conforming to stereotypes calling for men to be self-reliant and stoic associated with heightened levels of depression and psychological distress and promotes risky behaviors that impinge on men's health and longevity (Moss-Racusin, Phelan, \& Rudman, 2010, p. 141).

\section{Strategies/ solutions to Gender biases in the workplace}

\section{Phenomenon Based}

A current shift in accepting a person, regardless of gender, allows any organization or individual to benefit from the expertise of a person who sometimes might be overlooked or dismissed merely based on his or her physicality. Current research on gender equality has increasingly provided possible solutions to help reduce and ideally eliminate gender bias in the workplace. Many organizations have started to provide positive encouragement and reinforcements to employees surrounding gender equality. Listed below are some examples of how organizations can help advance gender equality in their work environment:

\section{Diverse Teams}

By allowing employees to participate in team-building exercises that include members of different genders and racial backgrounds, organizations can encourage employees to think outside the box. This team building gives a chance to intermingle with oneanother and eliminate the images or ideas they might have about a specific gender. ultimately, the employees will be able to breakdown the false and preconceived notions based on stereotypes.

\section{Workplace Audits}

The organizations that are willing to take a serious look at possible shortcomings with regards to gender equality should hire external auditors to review their hiring, training, and promotional processes. The audits will allow them to analyze how their operations previously and currently faired effectively. They can also enable the organization to review actual results and performances. By being transparent, an organization can show its commitment to progressive practices by implementing new processes to encourage and promote gender equality. This audit can then show the management's dedication to change in the culture. 


\section{Research-Based}

To minimize gender biases, organizations must build transparency from the beginning. Gender equality is fundamental to the success of a business. According to the Workplace Gender Equality Agency (2013), gender equality is achieved when people can access and enjoy the same rewards, resources, and opportunities regardless of whether they are women or men. Over the years, women have been paid continuously less than men. Dishman (2015) noted that "women represent nearly half (47\%) of the labor force in the United States and $40 \%$ of them in management, professional, and related jobs. Yet according to the most recent data from the U.S. Census, an average American woman who worked at least continuous hours a week earned $77.1 \%$ of what her male counterpart took home" (para. 1).

To fix this issue, some state agencies have started to make salaries known to the public. In 2011, Florida Governor Rick Scott established a websitewww.FloridaHasARightToKnow.com to inform employees about government spending. He stated (as cited in Bennett, 2011), "as taxpayers, you have the right to know how much of every taxpayer's dollar is spent. This new website will give you the tools you need to learn about state contracts, state employees' salaries, and regulations" (para. 5). By making salaries known to the public, organizations have started to minimize the questions that employees may have about how much is paid to them in comparison to another employee.

\section{Best Practices}

During my research and review of gender bias in the workplace, I discovered that gender discrimination is a common occurrence in most companies throughout the U.S. and the world. Based on statistics reported by the U.S. Bureau of Labor, on average, women earn $72 \%$ of what men earn for related occupations. Other vital statistics identified women as being more likely to have part-time positions (even in professional occupations) than men. Research reveals that women hold less than $15 \%$ of the corporate or upper-level management positions. Effective ways in which individuals and organizations can help minimize and ultimately eliminate gender bias in the workplace are as follows:

\section{- Familiarity with the Law}

By taking a severe interest in reducing and removing gender bias in the workplace, companies can ensure that the Human Resources Department, the Legal Department, and all the employees are familiar with the laws that govern equal employment and anti-discrimination activities.

\section{- Educate Employees}

"When people have heard how stereotypes work, they tend to scrutinize their decision-making more carefully. Women tend to break the tendency to use stereotypes as a shortcut" (Lorenz, 2014, para. 4). Employees should be reminded of the proverb, "if you know better than you will do better,"Once an employee is made aware of possible biases in his or her viewpoints, he or she can help initiate change or at the very least, acknowledge an issue. By being able to identify areas for possible development and growth concerning biases and discrimination, employees then take the necessary steps to start actively making a change.

\section{- Zero-Tolerance Policy}

As Dr. Sybil Mobley once stated, "no excuse is acceptable; no amount of effort is adequate until proven effective." When enough work, results, or behaviors are accepted, the mind frame and expectation level of people, students, employees, and organizations is easily altered (as cited in Florida A\&M University, 2013). Once organizations take a stand against any form of discrimination or bias, they can easily filter through the employees who perpetuate this type of thinking and behavior. By implementing this strategy, organizations can develop and ensure a healthier environment for employees to be more productive and attract high performing candidates who align with their cultures.

\section{Conclusion}

In sum, this paper has revealed that genderism is the discrimination caused due to the belief that one gender is superior to another. The notion that men are superior to women is problematic and needs critical examination because gender issues create severe matters in the workplace. It may create workplace conflict that has critical repercussions for the organizations as well as individuals working in those organizations. The write-up critically examined and discussed in detail the use of "isms" as the word bias or discrimination against people due to beliefs or perceptions, which do not have any scientific basis. The paper employed "isms" in the areas of socialization in terms of self-identity and its impact on the people, stereotyping relating to male and female, job promotion relating to male vs. female, and backlash concerning male and female all in the workplace. Also, this study identified various ways in which the use of "isms" would be eliminated in our workplaces 


\section{References}

Atwater, L. E., Carey, J. A., \& Waldman, D. A. (2001). Gender and discipline in the workplace: Wait until your father gets home. Journal of Management, 27(1), 537-561.

Bennett, L. (2011). Gov. Scott opens website, state salary database to public. Retrieved March 11, 2015, from http://www.wctv.tv/news/floridanews/headlines/Gov_Scott_Opens_State_Salary_Database_to_Public_118182 969.html

Dishman, L. (2015). A definitive strategy to eliminate the gender pay gap. Retrieved

March 12, 2015, from http://m.fastcompany.com/3042067/strong-female-lead/a-definitive-strategy-to-eliminate-thegender-pay-gap

Eagly, A. H., \& Karau, S. J. (2002). Role congruity theory of prejudice toward female leaders. Psychological Review, 109(3), 573-598.

Ensher, E. A., Vallone, E. J., Donaldson S. (2001). Effects of perceived discrimination on job satisfaction, organizational commitment, organizational citizenship behavior, and grievances. Human Resources Development Quarterly, 12(1), 53-72.

Estevez-Abe, M. (2005). Gender bias in skills and social policies: The varieties of capitalism perspective on sex segregation. New York, NY: Oxford University Press.

Florida A\& M University. (2013). SBI insights 2012-2013. Retrieved March

8, 2015, from http://www.famu.edu/sbi/userfiles/ifma/appendix\%203.2.10\%20sbi\% 20insights2012-2013.pdfHeilman, M. E. (2012). Gender stereotypes and workplace bias. Research in Organizational Behavior, 32(1), 113-135.

Johnson, K. Johnson. S, Joseph, D. \& Klutsey. J.C (2015). Gender Bias and Diversity in the Workplace

Lorenz, M. (2014). 6 ways to eliminate gender bias in the workplace. Retrieved March 10, 2015 from, http://thehiringsite.careerbuilder.com/2014/08/21/6-steps-eliminate-gender-bias-workplace/

Moss-Racusin, C. A., Phelan, J. E., \& Rudman, L. A. (2010). When men break the gender rules: Status incongruity and backlash against modest men. Psychology of Men \& Masculinity, 11(2), 140-151.

Moss-Racusin, C. A. \& Rudman, L. A. (2010). Disruption in women's self-promotion: The backlash avoidance model. Psychology of Women Quarterly, 34(1), 186-202.

Nickel, H., \& Vale, M. (1988). Sex-role socialization in relationships as a function of the division of labor. International Journal of Sociology, 18(3), 48-58.

O'Neill, O. A., \& O'Reilly C. A. (2011). Reducing the backlash effect: Self-monitoring and women's promotions. Journal of Occupational and Organizational Psychology, 84(4), 825-832.

Powell, G. N. \& Butterfield, D. A. (1994). Investigating the "glass ceiling" phenomenon: An empirical study of actual promotions to top management. The Academy of Management Journal, 37(1), 68-86.

Rudman, L. A., \& Phelan, J. E. (2008). Backlash effects for disconfirming gender stereotypes in organizations. Research in Organizational Behavior, 28(1), 61-79.

Sekaran, U., \& Bougie, R. (2013). Research methods for business: A skill-building approach (6 ${ }^{\text {th }}$ ed.). West Sussex, UK: Wiley \& Sons Ltd.

Shackelford, W. (2011).The new face of bias in the workplace: The subtlety of bias. Retrieved February 24, 2015, from http://www.workforcediversitynetwork.com/res_articles_newfaceofbias_Shackelford.aspx

Smith, A., \& Rogers, V. (2000). Ethics-related responses to specific situations vignettes: Evidence of gender-based differences and occupational socialization. Journal of Business Ethics,28(1), 73-86.

Soares, R. (2012). 2012 Catalyst census: Fortune 500 women executive officers and top earners. Retrieved March 1, 2015, from http://www.catalyst.org/knowledge/2012-catalyst-census-fortune-500-women-executive-officersand-top-earners

Stansbury, A. (2013). U.S. Bureau of Labor statistics 2013 report on women's earnings. Retrieved March 10, 2015, from http://journalistsresource.org

Steinpreis, R. E., Anders, K. A., \&Ritzke, D. (1999). The impact of gender on the review of the curricula vitae of job applicants and tenure candidates: A national empirical study. Sex Roles, 41(7), 509-527.

Ulkuer, N. (2006). Summary of UNGEI e-discussion on early gender socialization. Retrieved March 9, 2015, from http://www.ungei.org/cairo/docs/EarlyGenderSocialization_eDisc.pdf

Walker, H., Ilardi, B., McMahon, A., \& Fennell, M. (1996). Gender, interaction and leadership. Social Psychology Quarterly,59(3), 255-272.

Warner, J. (2014). The women's leadership gap: Women's leadership by the numbers. Retrieved March 9, 2015, from www.americanprogress.org

Workplace Gender Equality Agency. (2013). The business case for gender equality. Retrieved March 11, 2015, from https://www.wgea.gov.au/sites/default/files/business_case_for_gender_equality.pdf 